\title{
REVISTA JURÍDICA JUSTICIA AMBIENTAL. REVISTA DE DERECHO AMBIENTAL DE LA FISCALÍA DEL MEDIO AMBIENTE (FIMA).
}

\author{
Humberto Nogueira Alcalá ${ }^{1}$
}

En el ámbito nacional hacen falta publicaciones especializadas en el ámbito de derechos complejos como es el derecho medio ambiental, posibilitando la reflexión académica; el análisis de la legislación, la superación de sus vacíos y el mejoramiento de ella; el análisis, interpretación y aplicación del derecho internacional convencional y consuetudinario, que forma parte del derecho vigente y con aplicabilidad preferente respecto del derecho interno; el análisis de los fallos de nuestros tribunales superiores, con capacidad de determinación de aciertos y desaciertos, buscando siempre la crítica constructiva en pos del desarrollo de una adecuada interpretación, delimitación y aplicación de los derechos en la resolución del conflicto jurídico, a través de una sentencia suficientemente fundada, congruente y de acuerdo a las fuentes del derecho vigentes; todo ello con el objeto de contribuir a mejorar nuestro derecho y su aplicación, contribuyendo a preservar en mejor forma nuestro medio ambiente, nuestra calidad de vida y un desarrollo sustentable.

Nos encontramos en una época en que se ha tomado conciencia sobre la necesidad de proteger el medio o entorno para posibilitar la sobrevivencia del ser humano sobre la tierra, manteniendo un equilibrio básico con los recursos naturales renovables y no renovables que posibiliten el mantenimiento de un ambiente propicio a la mantención del desarrollo humano y una cierta calidad de vida humana. A partir de la segunda mitad del siglo XX se ha ido desarrollando la convicción de que una explotación indiscriminada de

1 Doctor en Derecho Constitucional. Profesor Titular de Derecho Constitucional y Director del Centro de Estudios Constitucionales de Chile. Director Magister en Derecho Constitucional, Universidad de Talca, Campus Santiago. Presidente de la Asociación Chilena de Derecho Constitucional. Vicepresidente del Instituto Iberoamericano de Derecho Procesal Constitucional. Miembro Asociado de la Academia Internacional de Derecho Comparado. 
los recursos naturales podría llevar a la destrucción del medio como hábitat adecuado para el desarrollo de la vida humana y la supervivencia de la especie, recursos que ya no tienen sólo un valor económico sino que se han convertido en objeto de tutela ambiental. Asimismo se ha tomado conciencia de las consecuencias negativas de un crecimiento económico incontrolado y contaminante que debe ser controlado para evitar que se impida la renovación de los recursos naturales o se imposibilita su utilización por las generaciones futuras. Ello ha transformado a los recursos naturales en bienes de carácter ambiental que deben ser preservados jurídicamente.

Así los ordenamientos jurídicos nacionales como el derecho internacional han debido asumir esta tarea, entendiendo que ella implica una tarea solidaria del conjunto de la humanidad y de cada uno de los estados que la componen. Siendo deber de cada Estado como del derecho internacional preservar la naturaleza para el desarrollo del género humano y una calidad de vida adecuada tanto para las generaciones actuales como venideras, conjugando el desarrollo económico social con la preservación básica del entorno o medio ambiente. Así surge un derecho ambiental estatal e internacional, el cual es tributario del conocimiento científico, el cual ha ido estableciendo los peligros y amenazas de la explotación indiscriminada de los recursos naturales y han ido aportando soluciones y medidas que deben adoptarse para combatir la contaminación, el deterioro climático y otros problemas acuciantes de nuestra época, generándose estándares consensuados que se convierten en normas jurídicas que fijan niveles máximos de contaminación o de calidad de los bienes ambientales.

Recientemente, el Programa de Naciones Unidas para el Medio Ambiente (PNUMA) integrado por representantes de una centena de países, en abril de 2007 ha emitido un informe, aprobado por el Consejo de Seguridad de Naciones Unidas de fecha 6 de abril de 2007, en que se considera que el cambio climático y la actividad contaminante humana, elevará la temperatura entre 1,5 y 2,5 grados, aumentando el nivel del mar, produciendo los consiguientes deshielos y fenómenos de sequías y se extinguirán alrededor del $30 \%$ de las especies con el consiguiente impacto para las formas de vida y sociedades humanas, impactando más fuertemente a los países más pobres de la Tierra.

Algunos documentos y medidas acordadas internacionalmente han sido señeras en la toma de conciencia sobre el deterioro creciente del clima y el medio ambiente, los cuales son expresión de la toma de conciencia de que los problemas climáticos y medio ambientales solo pueden afrontarse eficazmente en forma global o mundial y no a niveles solamente nacionales, dentro de lo cual constituye un hito señero la Conferencia de Naciones Unidas sobre el medio ambiente humano desarrollada en Estocolmo en 1972, a los cuales han seguido un conjunto de Documentos y Convenciones, dentro de los cuales cabe mencionar y destacar la "Declaración sobre el Cambio Climático" de Naciones Unidas de 1976, que promueve la protección ambiental, que luego da paso al programa de Naciones Unidas sobre Medio Ambiente, teniendo como uno de sus frutos la creación de la Comisión Mundial sobre Medio Ambiente y Desarrollo en 1983, desarrollándose sucesivas conferencias sobre el clima y medio ambiente, destacándose la Conferencia sobre el Medio Ambiente en Río de Janeiro en 1992, surgiendo el Convenio Marco sobre el Cambio Climático. 
El conjunto de estos documentos y convenciones plantea una soberanía limitada de los estados en materia de políticas ambientales destinada a mantener estándares mínimos que posibiliten y viabilicen una sociedad mundial ambientalmente sostenible. Ello nos permite afirmar la necesidad de integrar el derecho interno de los Estados con el derecho internacional en el logro de este objetivo vital para la sobrevivencia planetaria de la humanidad, lo que exige una solidaridad colectiva de los diversos estados, como una nueva aproximación cultual y jurídica de los operadores jurídicos nacionales, solo en tal perspectiva es posible afrontar los graves problemas que hoy enfrenta la humanidad por el deterioro del medio ambiente, entre los cuales a manera ejemplar puede mencionarse el cambio climático y todas sus consecuencias.

En tal perspectiva debemos entender el medio ambiente como un conjunto de relaciones y no de elementos, el cual comprende y no solo envuelve al hombre, abarcando los elementos naturales y culturales o artificiales por igual: seres humanos, entorno, componentes bióticos, abióticos y culturales.

En esta conceptualización quedan comprendidos los recursos naturales (aire, agua, suelo, subsuelo, fauna, flora, protección de especies amenazadas, costas, fondos marinos), como los elementos geológicos, químicos, biológicos y sociales que rodean e interactúan con los seres humanos condicionando su existencia y su desarrollo, como asimismo el de los demás seres vivos posibilitando su existencia, desarrollo o eventual desaparición; además deben considerarse también los recursos culturales, arquitectónicos, arqueológicos, entre otros, así como las relaciones que entre todos ellos se generan, tales como el clima, los ecosistemas, los espacios naturales, el paisaje. A esta perspectiva, debe añadirse las actividades potencialmente dañinas para el entorno ya sea por acción u omisión del ser humano, como asimismo, las medidas y acciones adoptadas para contrarrestarlas o impedirlas, con el objeto de mantener un equilibrio básico entre los diferentes factores, además de las acciones jurídicas para hacer efectiva la responsabilidad por el daño ambiental.

La mantención del equilibrio entre los distintos componentes del medio ambiente no solo debe darse entre ellos sino también en relación con el crecimiento económico y el consumo, con el objeto de brindar a las personas un entorno que posibilite su desarrollo y una adecuada calidad de vida. Esto hace del concepto de medio ambiente también un concepto relativo y enmarcado en un ámbito espacio temporal determinado, ya que cada generación tendrá su propia concepción sobre la armonía y equilibrio con los elementos que conforman el medio ambiente y su concepción sobre calidad de vida humana.

Los elementos que integran el concepto de medio ambiente mantienen entre sí complejas interrelaciones, las cuales impiden considerar al medio ambiente en forma estática, este tiene un carácter esencialmente dinámico producto del constante cambio o transformación a la que se encuentran sometidos los bienes ambientales de cuya protección hace responsable la Constitución a los órganos estatales y a la comunidad. 
A su vez, el derecho a un medio ambiente libre de contaminación es un concepto de carácter antropomórfico, en la medida que son los seres humanos quienes definen la calidad del entorno deseable y quienes han convertido ámbitos antes jurídicamente irrelevantes en derechos fundamentales y bienes constitucionalmente protegidos, todo lo cual responde a una perspectiva de calidad de vida y a las posibilidades de desarrollo de la vida humana en un contexto de recursos finitos y de un entorno cuya contaminación tolerable es limitada, especialmente teniendo presente una perspectiva de solidaridad intergeneracional.

Teniendo presente el conjunto de consideraciones anteriores estimamos que el derecho de las personas que se protege en el artículo $19 \mathrm{~N}^{\circ} 8$ de la Constitución, es el de vivir en un determinado medio ambiente, el cual debe ser adecuado para la vida humana, el desarrollo de la persona y sus potencialidades en sus diversos ámbitos, en interacción con el medio o entorno, donde los grados de contaminación se mantengan en un rango y por periodos que no degraden el ambiente del que forma parte la vida y el desarrollo humano, ya que hoy es utópico pensar en la ausencia total de contaminación, como asimismo, garantizando una naturaleza preservada y un respeto por el equilibrio ecológico.

En una redacción que consideramos poco afortunada, la Ley $\mathrm{N}^{\circ} 19.300$ sobre Bases Generales sobre el Medio Ambiente, en su artículo $2^{\circ}$ literal $\mathrm{m}$ ), precisa que se entenderá como medio ambiente libre de contaminación, "aquél en que los contaminantes se encuentran en concentraciones y periodos inferiores a aquéllos susceptibles de constituir un riesgo a la salud de las personas, a la calidad de vida de la población, a la preservación de la naturaleza o a la conservación del patrimonio ambiental". Consideramos que la disposición precedente citada debió referirse a niveles de contaminantes que afectaren la calidad ambiental dentro de la cual se encuentra la vida $y$ calidad de vida de las personas y no a un riesgo de la salud, ya que la protección de la salud se encuentra asegurada como derecho fundamental autónomo en otra disposición del artículo 19 de la Carta Fundamental, a ello debemos agregar que la cantidad de contaminantes que se requieren para afectar la calidad ambiental de vida de las personas que es lo que protege el artículo $19 \mathrm{~N}^{\circ} 8$ exige una regla más estricta que aquella que pueda afectar la salud de las personas asegurada por el artículo $19 \mathrm{~N}^{\circ}$ 9, la cual puede soportar mayores niveles de contaminación.

Este derecho actúa también como supremo principio ambiental, que condiciona toda la política ambiental de los diversos órganos estatales y obliga a conectarla y armonizarla con las demás políticas, ya que todas ellas deben basarse en el respeto integral de la dignidad de la persona humana, la que constituye una unidad en la que todos los derechos deben integrarse armónica y equilibradamente.

Los convenios y tratados internacionales suscritos por Chile en materia medio ambiental son desarrollo directo del artículo $19 \mathrm{~N}^{\circ} 8$ de la Carta Fundamental. Por ello el Estado chileno no puede tolerar actividades en su territorio con incidencia externa desfavorable al medio ambiente, debiendo considerar el impacto extraterritorial de 
sus normas ambientales. El Estado asume así gradual y coordinadamente con el resto de los Estados y sus pueblos una conducta y unas acciones destinadas a preservar el medio ambiente en el marco internacional.

Es necesario establecer que el derecho a disfrutar de un medio ambiente libre de contaminación tiene una dimensión de derecho prestacional, ya que exige al Estado y sus órganos desarrollar acciones tendientes a prevenir la contaminación o a descontaminar o a exigir determinadas acciones u omisiones de particulares destinadas a posibilitar la vida de las personas en un medio ambiente adecuado, como lo exige el inciso primero, segunda oración: "Es deber del Estado velar para que este derecho no sea afectado y tutelar la preservación de la naturaleza”.

Este artículo $19 \mathrm{~N}^{\circ} 8$ de la Carta Fundamental debemos relacionarlo asimismo con el inciso final del artículo $1^{\circ}$ de la Constitución en la tarea de promover condiciones de igualdad de oportunidades efectivas y reales para participar en la vida nacional, tanto de las personas individualmente consideradas como de los diversos grupos sociales en que ellas se integran, removiendo los obstáculos que impidan o dificulten la participación en la vida política, social, cultural y económica; todo ello requiere un medio ambiente adecuado para el desarrollo de las personas, el cual sólo puede ser producto y consecuencia de dichas condiciones adecuadas, por lo que el inciso final, frase final del artículo $1^{\circ} \mathrm{de}$ la Constitución requiere de una interpretación en clave ambientalista.

A su vez, el derecho a vivir en un medio ambiente libre de contaminación debe conectarse con la igualdad de oportunidades para participar en la vida nacional, que afirma el artículo $1^{\circ}$ inciso final de la Constitución, respecto de la adopción de decisiones y políticas públicas, las que en ciertas oportunidades no son coherentes con tal disposición constitucional cuando tienden a ubicar las actividades más contaminantes en las regiones más atrasadas o en los lugares en que vive la población más pobre y con menos poder de reacción política, lo que genera discriminación ambiental que es claramente contraria a los valores y principios afirmados por la Carta Fundamental, la que exige un reparto proporcionado y justo de las cargas, que es parte del principio de solidaridad y no concentrar la contaminación ambiental en los lugares donde viven los sectores más desfavorecidos y débiles de la población.

La dignidad humana y el derecho a vivir en un medio ambiente libre de contaminación requieren de la solidaridad y de políticas de reparto proporcionado y justo de las actividades contaminantes y sus costos en las diferentes regiones y sectores sociales. La Constitución no permite degradar desproporcionadamente la calidad de vida y el ambiente de los sectores más débiles de la población, ni en las regiones o localidades más pobres. La calidad de vida y el entorno adecuado debe garantizarse a todos por igual, asegurando un estándar de bienestar que posibilite el ejercicio de la libertad y la igualdad efectivas de todas las personas, la cual depende de las mejoras de las condiciones materiales y de la calidad de vida, la que debe hacerse efectiva para todos. De esta manera opera la función transformadora de la Constitución y la puesta del Estado al servicio de la persona y su desarrollo, dentro de los valores y principios constitucionales asegurados por el artículo $1^{\circ}$ de la Constitución. 
Este derecho no solo constituye una facultad de las personas, sino que es un derecho que tiene un deber correlativo, lo que significa que no sólo el Estado, sino cada una y todas las personas tienen que velar y responsabilizarse por la protección del medio ambiente, asumiendo en su caso su responsabilidad por el daño ambiental producido. Así cada persona tiene la facultad de defender su habitat, la biosfera y todo aspecto del medio ambiente ante actuaciones antijurídicas (arbitrarias o ilegales desarrolladas por terceros, sean agentes estatales o privados).

Los conceptos de preservación de la naturaleza y de conservación del patrimonio ambiental son conceptos constitucionalmente indeterminados, donde el legislador establece bases normativas para orientar la acción del juez constitucional en su tarea de delimitar y configurar tales conceptos que integran el derecho constitucional.

El concepto de preservación de la naturaleza ha sido considerado por la Ley $\mathrm{N}^{\circ} 19.300$ antes señalada, la que determina en su artículo $2^{\circ}$, literal p) que se entenderá por tal "el conjunto de políticas, planes, programas, normas y acciones destinadas a asegurar la mantención de las condiciones que hacen posible la evolución y el desarrollo de las especies y de los ecosistemas del país".

El concepto de preservación debe ser interpretado en conformidad con la Convención para la Protección de la Flora, la Fauna y las Bellezas Escénicas Naturales de América de 1940, conocida como Convención de Washington, ratificada por Chile en 1967, la cual vincula el concepto con la prohibición absoluta de explotación de recursos naturales como de realización de actividades comerciales con especies o áreas sujetas a preservación, lo que prohíbe totalmente la explotación de los recursos que formen parte del patrimonio de dicha área.

La norma constitucional establece el deber del Estado chileno no solo de no contaminar el entorno en niveles que afecten la calidad ambiental de vida de las personas y en evitar que miembros de la sociedad lo hagan, sino que debe asegurar también el derecho a vivir en un ambiente ecológico preservado y conservado.

A diferencia de la preservación, el concepto de conservación del patrimonio ambiental, tal como lo establece el artículo $2^{\circ}$, literal b) de la Ley $\mathrm{N}^{\circ} 19.300$, posibilita "el uso y aprovechamiento racionales o la reparación, en su caso, de los componentes del medio ambiente, especialmente aquellos propios del país que sean únicos, escasos o representativos, con el objeto de asegurar su permanencia y su capacidad de regeneración”. Ello permite una cierta actividad económica que sea compatible con el área mediante una explotación racional de tales recursos.

Los conceptos legales mencionados de preservación de la naturaleza y conservación del patrimonio ambiental discurren bajo niveles diferentes de exigencia de incontaminación o de niveles de contaminación, siendo más exigente el primer concepto que exige mantener preservados los ecosistemas, mientras el segundo sólo exige un uso racional de los elementos del medio ambiente dentro de los parámetros de un desarrollo sustentable.

Esta concepción exige explicitar que el uso racional de los recursos para preservar la 
naturaleza y conservar el patrimonio ambiental implica asumir una concepción y un principio de desarrollo sustentable que posibilite la satisfacción de las necesidades de las generaciones presentes sin comprometer la calidad del ambiente de las generaciones futuras en un contexto de solidaridad intergeneracional, teniendo presente la capacidad del sistema natural para neutralizar los efectos negativos derivados de la actividad humana sobre el ambiente o entorno, lo que permite determinar el acrecentamiento o disminución del capital ambiental de las generaciones futuras. La solidaridad intergeneracional implica la obligación de respeto y aseguramiento de los principios de conservación de opciones, de la conservación de la calidad y de la conservación del acceso.

A su vez, en esta materia como en otras referentes a derechos fundamentales, debe hacerse efectivo el principio de precaución que determina que quienes deben adoptar decisiones legislativas, administrativas o jurisdiccionales deben adoptar medidas transitorias que posibiliten preservar el ambiente mientras no avance el conocimiento científico y técnico, y disminuya o desaparezca la incertidumbre acerca del efecto producido por dicha acción en la calidad ambiental. En tal perspectiva la declaración de Wingspread determina que cuando una actividad representa una amenaza para el medio ambiente, deben adoptarse medidas precautorias, aun cuando algunas relaciones de causa a efecto no hayan sido totalmente determinadas de manera científica.

La Constitución autoriza así al legislador para establecer restricciones específicas a ejercicio de otros derechos fundamentales para proteger el medio ambiente. Por otra parte, el artículo $19 \mathrm{~N}^{\circ} 24$ que delimita el derecho de propiedad, establece también como elementos que integran las obligaciones que derivan de la función social de la propiedad la conservación del patrimonio ambiental.

La disposición constitucional se refiere a restricciones específicas lo que significa que el legislador debe establecer y determinar los derechos concretos que se verán afectados por las restricciones y las medidas especiales que pueden adoptarse con dicha finalidad.

La titularidad del derecho a vivir en un medio ambiente adecuado tiene un carácter erga omnes, lo que posibilita el uso del recurso de protección como una especie de acción popular o pública, en la medida que el derecho a la protección del medio ambiente es un derecho cuya degradación afecta a toda la comunidad, ya que sus efectos impactan el medio en el cual todos vivimos.

Los titulares del derecho, vale decir, todas las personas, pueden legítimamente accionar, cuando por un acto u omisión ilegal o arbitrario no sólo se contamina afectando la calidad de vida, sino también cuando no se preserva la naturaleza o no se conserva el patrimonio ambiental, indistintamente de la cercanía o lejanía geográfica de quienes impugnen la acción u omisión antijurídica respectiva.

La titularidad del medio ambiente pertenece a todos quienes integran la sociedad, constituye un bien público no susceptible de apropiación exclusiva de nadie, por lo cual los tribunales deben actuar en esta materia como en el ámbito de los demás derechos fundamentales, con el principio in dubio pro ambiente y en materia de legitimación activa en materia de recurso de protección con el principio in dubio pro accione. 
Por otra parte, es necesario señalar que, en el ordenamiento jurídico chileno, aún se mantiene una concepción tradicional y bastante superada de responsabilidad por daño ambiental, consistente en un enfoque jurídico de una presunción meramente legal de responsabilidad por dicho daño. La tendencia actual en el derecho comparado es la de considerar una responsabilidad objetiva, como lo establece en general el derecho europeo en el Libro Blanco de la Unión Europea, por una parte, como el derecho anglosajón, por otra.

La Revista Justicia Ambiental ofrece un espacio para el análisis de las diversas dimensiones y materias propias del derecho ambiental, siendo un espacio abierto y plural, el cual debe ser aprovechado por todos los operadores jurídicos que trabajan o que tienen interés en el desarrollo del derecho ambiental, como asimismo, contribuye a llenar un vacío de una tribuna especializada en el medio nacional, donde no existía hasta ahora una publicación periódica como la que ofrece la revista que hoy presentamos.

En ella hay espacio para la presentación de estudios como investigaciones y artículos académicos y profesionales sobre las materias de derecho ambiental como los que se presentan en el presente número sobre "Energías Renovables", "Reflexiones sobre algunos principios y valores que regulan el medio ambiente en Chile"; estudios de derecho comparado o de derecho internacional ambiental como el dedicado a las "Normas Suizas de Protección Ambiental y su aplicación en Chile" y "El régimen jurídico internacional aplicable a la pesca marítima", y "Las Aguas como Bien Nacional de Uso Público"; análisis de ámbitos procesales y estrategias de litigio nacional o internacional, como el estudio sobre "Estrategia para el litigio de casos ambientales ante el sistema interamericano de derechos humanos". Como asimismo, como toda revista jurídica que se precie, tiene una sección de comentarios de jurisprudencia, en el cual se analizan sentencias destacadas de los tribunales en las cuales se destacan principios del derecho ambiental y su aplicación por los tribunales, como es el caso del análisis jurisprudencial en base a sentencias de Corte de Apelaciones y Corte Suprema acerca de "La responsabilidad civil derivada del daño ambiental" ; el análisis del "Por qué es importante el fallo PROMEL para el derecho público"; y los Comentarios sobre el fallo de la Corte de Apelaciones de Santiago en el caso PELAMBRES”.

Esperamos que este primer número de la Revista Justicia Ambiental, con la riqueza de su análisis sobre temas centrales del derecho ambiental, como asimismo de análisis de importantes fallos de nuestros tribunales superiores de justicia, sean el inicio de una publicación periódica que se mantenga en el tiempo, la que, sin duda, alimentará a los diversos operadores jurídicos del derecho ambiental, como asimismo a los académicos de dicha área.

Deseamos para Justicia Ambiental el mejor de los éxitos en su tarea de análisis, profundización y socialización del derecho ambiental en el medio académico, profesional y jurisdiccional chileno, como asimismo, en todos los interesados en una mejor calidad de vida y de desarrollo sustentable para Chile. 